Tropical Journal of Pharmaceutical Research June 2016; 15 (6): 1313-1320

ISSN: $1596-5996$ (print); 1596-9827 (electronic) (C) Pharmacotherapy Group, Faculty of Pharmacy, University of Benin, Benin City, 300001 Nigeria.

All rights reserved.

\title{
Factors associated with hypoglycemia episodes in hospitalized type 2 diabetes mellitus patients in a tertiary health facility in Malaysia
}

\author{
Hasniza Zaman Huri ${ }^{1,2 *}$, Muhammad Irfan Abdul Aziz ${ }^{1}$, Shireene Ratna \\ Vethakkan $^{3}$ and Riyanto Teguh Widodo ${ }^{1}$ \\ ${ }^{1}$ Department of Pharmacy, Faculty of Medicine, University of Malaya, 50603 Kuala Lumpur, ${ }^{2}$ Clinical Investigation Centre, 13th \\ Floor Main Tower, University Malaya Medical Centre, 59100 Lembah Pantai, Kuala Lumpur, ${ }^{3}$ Endocrinology Unit, Department \\ of Medicine, Faculty of Medicine, University of Malaya, 50603 Kuala Lumpur, Malaysia \\ *For correspondence: Email: hasnizazh@um.edu.my; Tel: +603 79676659
}

\begin{abstract}
Purpose: To determine the factors associated with severity of hypoglycemia in hospitalized type 2 diabetes mellitus patients in a tertiary health facility in Malaysia.

Methods: This retrospective study involved 207 hospitalised T2DM patients with hypoglycaemia episodes from January 2008 to December 2012 and was conducted in University Malaya Medical Centre, Petaling Jaya, Malaysia. Patients were classified into 2 groups, viz, those who had hypoglycaemia on admission and those who had hypoglycaemia during hospital stay. Patients with hypoglycemia on admission were those admitted due to hypoglycemia while patients with hypoglycemia during hospital stay were those admitted due to other causes but subsequently developed hypoglycemia during hospitalization.

Results: The results for the 207 patients investigated show that most of the patients (72.2\%) were asymptomatic during hypoglycemic episodes. The majority of the episodes (57.4\%) experienced by the patients were mild hypoglycemia $(<3.9 \mathrm{mmol} / \mathrm{L})$. Old age $(p=0.011)$ and presence of stroke $(p=0.033)$ were found to be significantly associated with severe hypoglycemia $(<2.2 \mathrm{mmol} / \mathrm{L})$ while concurrent use of opioid $(p=0.008)$ was associated with mild hypoglycemia.

Conclusion: The identification of the underlying factors associated with severity of hypoglycemia may help in preventing and resolving hypoglycemia in T2DM patients.
\end{abstract}

Keywords: Hypoglycemia episodes, Type 2 diabetes, Associated factors, Elderly, Stroke, Opiods

Tropical Journal of Pharmaceutical Research is indexed by Science Citation Index (SciSearch), Scopus, International Pharmaceutical Abstract, Chemical Abstracts, Embase, Index Copernicus, EBSCO, African Index Medicus, JournalSeek, Journal Citation Reports/Science Edition, Directory of Open Access Journals (DOAJ), African Journal Online, Bioline International, Open-J-Gate and Pharmacy Abstracts

\section{INTRODUCTION}

Diabetes mellitus is an emerging global epidemic and is the main illness threatening human health in 21st century [1]. In Malaysia, the prevalence of diabetes mellitus in 1986 as reported by National Morbidity Health Survey (NHMS) is $6.3 \%$ [2]. The figure has risen to $8.3 \%$ in 1996 and $14.9 \%$ in $2006[2,3]$. In 2012, the figure has achieved $20.8 \%$ of populations [4]. WHO forecasted that
2.48 millions of Malaysians will be suffering from diabetes mellitus in 2030 [5]. Type 2 diabetes mellitus (T2DM) constitutes $85-95 \%$ of diabetes mellitus cases in developed countries [6].

The target clinical outcomes in patients with T2DM is good control of fasting blood glucose level which is less than $7.2 \mathrm{mmol} / \mathrm{L}$ and $\mathrm{A} 1 \mathrm{C}$ less than $7 \%$ [7]. However, aggressive treatment is needed to achieve this target in some patients 
[8]. This aggressive treatment predisposes patients to a higher risk of hypoglycemia that become a major hurdle in achieving glycemic goal in these patients [9]. Patients treated with exogenous insulin as well as insulin secretagogues such as sulphonylureas (SUs) and meglititnides are at higher risk of getting hypoglycemia episodes $[9,10]$. Besides, the present of other co-morbidities such as renal failure, liver disease, adrenal deficiency and hypopituitarism also predispose patients to higher risk of hypoglycemia $[11,12]$.

Hypoglycemia may affect patients' daily life in which the patients experienced troubling symptoms for instance shakiness, anxiety, sweating and irritability [13]. In serious condition, it may lead to coma, seizure and even may lead to fatal [8]. Hypoglycemia often goes undetected not only by the patients but also by health care providers (HCPs) [8]. In view of serious and lifethreatening effect of hypoglycemia, it is crucial for HCPs to understand the clinical factors associated with hypoglycemia so that appropriate precaution and management can be taken to prevent further episodes of hypoglycemia.

This study was aimed to investigate the severity of hypoglycemia episodes and clinical factors associated with its severity in T2DM patients. Hence, data obtained from this study may be used to assist the HCPs to enhance and improve the overall management of hypoglycemia during hospitalization.

\section{EXPERIMENTAL}

\section{Sample population, sampling frame and sampling size}

The study population consisted of hospitalised type 2 diabetes mellitus (T2DM) patients with hypoglycaemia episodes. Patients were classified into 2 groups, those who had hypoglycaemia on admission and those who had hypoglycaemia during hospital stay. Patients with hypoglycemia on admission were those admitted due to hypoglycemia while patients with hypoglycemia during hospital stay were those admitted due to other causes but subsequently develop hypoglycemia during hospitalization.

The study employed a convenient sampling method from January 2008 to December 2012. The minimum sample size of this study was calculated using Epi Info Program Version 7.0 (CDC, Clifton Rd. Atlanta, USA). A minimum of 108 patients were needed to give a power of $\beta=$ 0.8 and confidence level of $95 \%$ for this study.

\section{Study design and procedures}

This was a retrospective study conducted in a premier teaching hospital in Malaysia with 1200 beds, which was the University of Malaya Medical Centre (UMMC), Malaysia. This study was conducted in accordance to Declaration of Helsinki and was approved by the Medical Ethics Committee (MEC) of UMMC (ref no.956.34). MEC of UMMC waived the need for written informed consent from the participants.

A total of 1167 potential patients were identified via the Hospital Information System (HIS) based on International Statistical Classification of Diseases and Related Health Problems 10th Revision (ICD-10) for T2DM (E11.0-E11.9). In the end, 207 patients who fulfilled the inclusion criteria were included in this study. Adult T2DM aged at least 18 years old, all hospitalized T2DM patients with at least one hypoglycemia episode, T2DM patients admitted with hypoglycemia episode and T2DM patients who were admitted to general medical units were included whilst T2DM patients without hypoglycemia episode and patients with other types of diabetes were excluded in the study.

Definition of few terms that was used in this study is shown below to ensure the consistency of results (Table 1). There were three categories of information has been collected which were demographic characteristics (such as age, gender, ethnicity), clinical characteristics (such as duration of diabetes, body mass index, smoking habit, alcohol intake, comorbidities that require long term drug treatments and concurrent medications during hospital stay) and hypoglycemia profiles (such as blood glucose readings, drugs that cause hypoglycemia, symptoms of hypoglycemia and treatment of hypoglycemia). The definition of terms used in study are listed below.

\section{Data analysis}

All extracted data were pooled and analyzed using the Statistical Package for the Social Science (SPSS) software version 20.0 (SPSS Inc., Chicago, IL., USA). Continuous data such as age was tested for normality using ShapiroWilk Test. A normally distributed result was expressed as mean \pm standard deviation (SD). For categorical data, Chi-square test was used to determine the association of patients' characteristics with severity of hypoglycemia episodes. When the expected cell counts for $>$ $20 \%$ was less than 5, Monte-Carlo Exact Test was used. On the other hand, independent T-test was used to compare mean between groups for 
continuous data such as mean blood glucose level on admission and during hospital stay. The statistical significance was assumed at $p<0.05$ in this study.

\section{RESULTS}

\section{Study subject's disposition}

A total of 207 patients were included in the study. Male patients have about an equal proportion with female patients in this study. The nonelderly group of patients was slightly more than elderly group. The Shapiro-Wilk Test showed that the age of patients was normally distributed. The mean \pm standard deviation (SD) of patients' age was $62.5 \pm 12.2$ years old with the minimum and maximum age were 30 and 97 years old respectively. Indian was the most common ethnic group in this study. This was followed by Malays, Chinese and others ethnics. The demographic characteristics of subjects were shown in Table 1. Majority of the patient population had duration of T2DM of less or equal to 10 years. Most subjects had their BMI in normal range $(5.3 \%)$ and $2.9 \%$ were obese. On the other hand, half of the patients in this study were non-smoker $(50.7$ $\%)$. Results also showed that $6.3 \%$ of subjects consume alcohol. Hypertension (80.2\%) and renal impairment $(33.3 \%)$ were the two most common comorbidities found whereas the two leading concurrent medications were penicillin $(61.3 \%)$ and statins (54.8\%).

\section{Profile of hypoglycemia episodes}

A total of 207 patients were included in this study with 248 admissions. From 248 admissions, there were 566 hypoglycemia episodes experienced by the patients. Majority of patients (82.7 \%) experienced hypoglycemia episodes during hospital stay.

\section{Mean of blood glucose level}

There was a trend towards lower mean blood glucose level in patients with hypoglycemia episodes on admission ( $2.3 \mathrm{mmol} / \mathrm{L})$ compared to those during hospital stay $(3.1 \mathrm{mmol} / \mathrm{L})$. The trend of mean blood glucose level between these 2 groups was analyzed using independent sample T-test and it was found that patients who experienced hypoglycemia episodes on admission had significantly lower mean blood glucose level $(p<0.0001)$.

\section{Causes associated with hypoglycemia episodes in T2DM patients}

The main cause of hypoglycemia in T2DM patients is absolute or relative insulin excess due to exogenously administered insulin preparations or administration of OHAs that stimulate the endogenous insulin secretion such as sulphonylureas (Table 2). In addition to insulin and OHAs, hypoglycemia could be potentiated by poor oral intake that could further reduced blood glucose level and predisposed patient to hypoglycemia as reflected in the Table 3.

\section{Association between causes and severity of hypoglycemia}

It was found that insulin was associated with mild hypoglycemia (Table 3). Besides that, OHAs and concurrent loss of appetite was highly associated with moderate hypoglycemia.

\section{Severity of hypoglycemia episodes}

About half of the episodes $(57.4 \%$ ) reported were mild hypoglycemia. Moderate and severe hypoglycemia represents about 30 and $12 \%$ of the episodes respectively.

\begin{tabular}{|c|c|c|}
\hline Characteristics & Definition & Ref \\
\hline Demographic & $\begin{array}{l}\text { 1) Elderly } \\
\text { - Older adults above } 64 \text { years old }\end{array}$ & [14] \\
\hline Acute complication & $\begin{array}{l}\text { 1) Hypoglycemia } \\
\text { - Blood glucose less than } 3.9 \mathrm{mmol} / \mathrm{L} \\
\text { 2) Severity of hypoglycemia } \\
\text { - Mild hypoglycemia referred to blood } \\
\text { glucose level less than } 3.9 \mathrm{mmol} / \mathrm{L} \\
\text { - Moderate hypoglycemia referred to } \\
\text { blood glucose level less than } \\
3.1 \mathrm{mmol} / \mathrm{L} \\
\text { - Severe hypoglycemia referred to } \\
\text { blood glucose level less than } \\
2.2 \mathrm{mmol} / \mathrm{L}\end{array}$ & $\begin{array}{l}\text { [7]; } \\
\text { [15] }\end{array}$ \\
\hline
\end{tabular}


Table 1: Demographic and clinical characteristics of patients $(N=207)$

\begin{tabular}{lr}
\hline Demographic and clinical & $\begin{array}{r}\text { Number of } \\
\text { chatients }(\%)\end{array}$ \\
\hline Gender & $101(48.8)$ \\
Male & $106(51.2)$ \\
Female & \\
Age & $119(57.5)$ \\
Non-elderly & $88(42.5)$ \\
Elderly & \\
Ethnicity & $80(38.6)$ \\
Malay & $45(21.7)$ \\
Chinese & $81(39.1)$ \\
Indian & $1(0.5)$ \\
Others & \\
Duration of diabetes & $38(18.4)$ \\
s10 years & $17(8.2)$ \\
11-20 years & $12(5.8)$ \\
$21-30$ years & $2(1.0)$ \\
$\geq 31$ years & $138(66.7)$ \\
Unknown & \\
BMl & $5(2.4)$ \\
Underweight $(<18.5)$ & $11(5.3)$ \\
Normal range $(18.5-24.9)$ & $9(4.3)$ \\
Pre-obese $(25-29.9)$ & $6(2.9)$ \\
Obese $(\geq 30)$ & $176(85.0)$ \\
Unknown & \\
Smoking & $18(8.7)$ \\
Yes & $105(50.7)$ \\
No & $23(11.1)$ \\
Ex-smoker & $61(29.5)$ \\
Unknown & $13(6.3)$ \\
Alcohol & $114(55.1)$ \\
Yes & $6(2.9)$ \\
No & $74(35.7)$ \\
Ex-drinker & $B M 1=(W / g h t$ \\
Unknown & \\
\hline
\end{tabular}

* Non-elderly-less than 65 years old; elderly- 65 years old or more; ${ }^{*} B M I=$ Weight $(\mathrm{kg}) \div\left\{\left[\right.\right.$ Height $x$ Height $\left.\left(\mathrm{m}^{2}\right)\right\}$

Table 2: Causes associated with hypoglycemia episodes $(\mathrm{N}=207)$

\begin{tabular}{lccc}
\hline $\begin{array}{l}\text { Cause of } \\
\text { hypoglycemia }\end{array}$ & \begin{tabular}{c} 
On admission \\
\cline { 2 - 3 }
\end{tabular} & $\begin{array}{c}\text { During hospital stay } \\
\mathbf{( \% )}\end{array}$ & $\begin{array}{c}\text { Total } \\
\mathbf{( \% )}\end{array}$ \\
\hline Insulin & $22(3.9 \%)$ & $\mathbf{N}=\mathbf{5 6 6}$ \\
OHAs & $12(2.1 \%)$ & $382(67.5 \%)$ & $404(71.4 \%)$ \\
Insulin $+{ }^{\#}$ LOA & $4(0.7 \%)$ & $17(3 \%)$ & $29(5.1 \%)$ \\
OHAs $+{ }^{\#}$ LOA & $31(5.5 \%)$ & $0(0 \%)$ & $4(0.7 \%)$ \\
$\#$ LOA & $5(0.9 \%)$ & $1(0.2 \%)$ & $32(5.7 \%)$ \\
Unknown & $24(4.2 \%)$ & $1(0.2 \%)$ & $6(1.1 \%)$ \\
\hline
\end{tabular}

"OHAs - Oral Hypoglycemic Agents; ${ }^{*}$ LOA - Loss of Appetite

Table 3: Association between causes and severity of hypoglycemia episodes

\begin{tabular}{lcccc}
\hline Cause of & \multicolumn{3}{c}{ Severity of hypoglycemia } & ${ }^{\circ} \boldsymbol{P}$-value \\
hypoglycemia & Mild & Moderate & Severe & \\
\cline { 2 - 4 } Insulin & $238(58.9 \%)$ & $128(31.7 \%)$ & $38(9.4 \%)$ & $0.0001^{\mathrm{b}}$ \\
OHAs & $17(58.6 \%)$ & $6(20.7 \%)$ & $6(20.7 \%)$ & \\
Insulin + LOA & $1(25 \%)$ & $1(25 \%)$ & $2(50 \%)$ & \\
OHAs + LOA & $10(31.2 \%)$ & $12(37.5 \%)$ & $10(31.2 \%)$ & \\
LOA & $1(16.7 \%)$ & $1(16.7 \%)$ & $4(66.7 \%)$ & \\
Unknown & $58(63.7 \%)$ & $24(26.4 \%)$ & $9(9.9 \%)$ & \\
\hline
\end{tabular}

${ }^{*}$ Severity of hypoglycemia reported as number of episodes (percentage across row, \%); ${ }^{\delta}$ degree of freedom $=$ 10; ${ }^{b}$ Monte Carlo Exact Test 
Table 4: Factors significantly associated with severity of hypoglycemia episodes

\begin{tabular}{|c|c|c|c|c|}
\hline \multirow[t]{2}{*}{ Characteristic } & \multicolumn{3}{|c|}{ *Severity of hypoglycemia } & \multirow[t]{2}{*}{${ }^{\circ} \boldsymbol{P}$-value } \\
\hline & Mild & Moderate & Severe & \\
\hline \multicolumn{5}{|l|}{ Age } \\
\hline Non-elderly & $196(61.2 \%)$ & $96(30 \%)$ & $28(8.8 \%)$ & \multirow{2}{*}{$0.011^{\mathrm{a}}$} \\
\hline Elderly & $129(52.4 \%)$ & $76(30.9 \%)$ & $41(16.7 \%)$ & \\
\hline \multicolumn{5}{|l|}{ Stroke } \\
\hline Present & $49(55.1 \%)$ & $22(24.7 \%)$ & $18(20.2 \%)$ & \multirow[t]{2}{*}{$0.033^{a}$} \\
\hline $\begin{array}{l}\text { Absent } \\
\text { Opioid }\end{array}$ & $276(57.9 \%)$ & $150(31.4 \%)$ & $51(10.7 \%)$ & \\
\hline Yes & $127(66.1 \%)$ & 49 (25.5\%) & $16(8.3 \%)$ & \multirow[t]{2}{*}{$0.008^{a}$} \\
\hline No & $198(52.9 \%)$ & $123(32.9 \%)$ & $53(14.2 \%)$ & \\
\hline
\end{tabular}

Table 5: Comparison of the regimens of opioid with severity of hypoglycaemia

\begin{tabular}{lcccc}
\hline Opioid & \multicolumn{3}{c}{${ }^{*}$ Severity of hypoglycemia } & \multirow{2}{}{${ }^{\circ} \boldsymbol{P}$-value } \\
\cline { 2 - 4 } & Mild & Moderate & Severe & \\
\hline Tramadol $50 \mathrm{mg}$ & $124(66 \%)$ & $49(26.1 \%)$ & $15(8 \%)$ & $0.055^{\mathrm{D}}$ \\
Morphine $1 \mathrm{mg}$ & $1(100 \%)$ & $0(0 \%)$ & $0(0 \%)$ & \\
Morphine $2 \mathrm{mg}$ & $2(66.7 \%)$ & $0(0 \%)$ & $1(33.3 \%)$ & \\
Not on opioid & $198(52.9 \%)$ & $123(32.9 \%)$ & $53(14.2 \%)$ & \\
\hline
\end{tabular}

${ }^{*}$ Severity of hypoglycemia reported as number of episodes (percentage across row, \%); ${ }^{\delta}$ degree of freedom $=6$;

${ }^{b}$ Monte Carlo Exact Test

\section{Factors significantly associated with severity of hypoglycemia}

Three factors, which were age, presence of stroke and concomitant use of opioid during the hospitalization were found to be significantly associated with the severity of hypoglycemia in T2DM patients $(p<0.05)$. Elderly group is more likely to have severe hypoglycemia compared to non-elderly group. Besides that, patient suffered from stroke had higher probability having severe hypoglycemia compared to patient without stroke. On the other hand, concomitant use of opioid during hospitalization is highly associated with mild hypoglycemia. Table 4 summarized the factors that significantly associated with severity of hypoglycemia episodes.

Since significant association was found between opioid and severity of hypoglycemia, we next analyze the dosing regimen of opioid associated with hypoglycemia. However, there is no significant association was found between dosing regimens and severity of hypoglycemia (Table 5 ).

\section{DISCUSSION}

Hypertension was the most common comorbidity among the patients in this study $(80.2 \%)$ and this has also been the case in general in which it has been reported that more than $80 \%$ of Malaysian adults' diabetic patients has hypertension [16]. It has also been shown that hypertension was one of the most common comorbidity among T2DM patients in United State $(67 \%)$ [17]. There are many underlying pathophysiological mechanism that has been proposed to explain how diabetes can cause hypertension such as the stimulatory effect of hyperinsulinemia on sympathetic tone and the excitatory effect of hyperglycemia on the renninangiotensin aldosterone (RAAS) system [18]. An additional risk factor such as lipid abnormalities may further increase the risk of hypertension in diabetes patients [7]. In this study, around $13 \%$ of patients had dyslipidemia.

Besides that, renal impairment's comorbidity contributed around $30 \%$ of patients in this study. However, study by Rajbharan et al [19] showed that only $20 \%$ of T2DM patients had complication of renal impairment. The contrary of results could be due to quite a substantial proportions $(13 \%)$ of the patients in this study had dyslipidemia. There are evidences that lipid abnormalities may increase the risk of renal impairment $[20,21]$. These studies reported lipid fractions may induce mediators such as cytokines, reactive oxygen species and chemokines or through hemodynamic changes way to cause injury to both glomerular and tubulointerstitial injury. However, another study by John et al [20] suggested the important role of triglyceride that specifically produces reactive oxygen species that leads to the damage of glomerulus [20]. Therefore, there is higher 
percentage of renal impairment in this study population.

This study also found that antihypertensive agents that inclusive beta-blockers (23\%), calcium channel blockers (40.7\%), loop diuretics $(10.5 \%)$ and ACE inhibitors (32.7\%) in T2DM patients with hypoglycemia episodes. The high prescribing rate of antihypertensive agents concurred with the fact that hypertension was the most common comorbidities encounter in this study. This finding was supported by a local population study that showed a high percentage $(75 \%)$ of diabetes patients that received antihypertensive agents concurrently [16].

Besides that, the use of statins was also commonly seen in T2DM patients within this study. This is in line with the Malaysian Clinical Practice Guideline (CPG) on Management of T2DM in which all diabetic patients without overt cardiovascular disease (CVD) over the age of 40 years and all patients with overt CVD should be treated with a statin regardless of baseline low density lipoprotein (LDL) cholesterol level [22]. Patients of age above 40 years old constitute around $95 \%$ of population in this study.

Antibiotics such as penicillin (61.3\%) and cephalosphorin $(21 \%)$ were among the most commonly prescribed medications in the cohort. This use of antibiotics was in agreement with the report from Centre for Healthcare Research \& Transformation, University of Michigan (2011). Antibiotics were commonly used in diabetic patients because they are predisposed to the infections such as pneumonia, pyelonephritis and soft tissue infection including diabetic foot ulcer. The risk of getting infections is especially higher in the diabetic patients with cardiovascular disease comorbidities as shown in a study by Bertoni et al [23].

Of all episodes of hypoglycemia, mild hypoglycemia had the highest proportion (57.4 $\%)$ followed by moderate $(30.4 \%)$ and the least was severe hypoglycemia (12.2\%). This trend was also observed by another study that include cohort in the same setting (UMMC) in which mild, moderate and severe hypoglycemia accounted for $46.3 \%, 33.3 \%$ and $20.4 \%$ respectively [24]. Nevertheless, different definition was used to classify the severity of hypoglycemia as that study classified the patients based on symptoms while in our study patients were classified based on blood glucose readings.

Age was found to be significantly associated with severe hypoglycemia $(p=0.011)$. This has also been reported by other authors [8,25]. Elderly patients are prone to severe hypoglycemia because the aging process modifies the counterregulatory response to become less effective in preventing hypoglycemia. Besides that, elderly patients have attenuated hypoglycemia response and the symptoms are usually present at severe stage of hypoglycemia [26]. Diminished autonomic symptoms such as fatigue and headache leads to late diagnosis of hypoglycemia and therefore elderly patients usually present to the hospitals with severe hypoglycemia [25].

Presence of stroke was found to be significantly $(p=0.033)$ associated with severe hypoglycemia. This observation could be due to poor glycemic control in stroke patients as researches have found that high blood glucose is associated with higher risk of macrovascular complications including stroke [27]. Poor glycemic controls are usually treated with aggressive insulin and OHAs therapy that in turn predispose patient to higher risk of hypoglycemia $[8,9]$. This explains why there is high incidence of severe hypoglycemia were observed in patient with stroke.

Additionally, the association of stroke with severe hypoglycemia could be cofounded with patients' age because the majority of patients which present with stroke are elderly $(76.7 \%)$ and as discussed earlier, advanced age was a significant predictor of more severe hypoglycemia in this study and other previously published studies $[8,25]$.

\section{Opioid}

The use of opioid was found to be significantly associated with mild hypoglycemia ( $p=0.008$ ). Up to date, there are no clinical studies that have demonstrated this finding but there are 4 case reports of tramadol-induced hypoglycemia, which has been published in PubMed [28,29]. However, the underlying mechanisms of opioid induced hypoglycemia are unclear [29].An animal study in mice has also demonstrated the glucose lowering effect of methadone which is also an opioid but the mechanism remain unknown [30].

\section{CONCLUSION}

Approximately half of the episodes seen in this study are mild hypoglycemia followed by moderate and severe hypoglycemia. Factors identified to associate with severe hypoglycemia include elderly age and presence of stroke while concurrent use of opioid was associated with mild hypoglycemia. The identification of underlying factors associated with severity of 
hypoglycemia may help in preventing and resolving hypoglycemia in T2DM patients. Hence, more attention is required for patients having multiple of these risk factors.

\section{ACKNOWLEDGEMENT}

The authors would like to thank Ministry of Science, Technology and Innovation, Malaysia (Science fund: no. 12-02-03-2097) and University of Malaya, Malaysia (no. RP024C-14HTM) for financial and technical support.

\section{DECLARATIONS}

\section{Conflict of Interest}

No conflict of interest associated with this work.

\section{Contribution of Authors}

The authors declare that this work was done by the authors named in this article and all liabilities pertaining to claims relating to the content of this article will be borne by them.

\section{REFERENCES}

1. Moser EG, Morris AA, Garg SK. Emerging diabetes therapies and technologies. Diabetes Res Clin Pract 2012; 97(1): 16-26.

2. Mastura I, Zanariah H, Fatanah I, Idzwan MF, Wan Shaariah MY, Jamaiyah $\mathrm{H}$, et al. An Audit of Diabetes Control and Management (ADCM). Med J Malaysia 2008; 63: 76-77.

3. Zanariah $H$, Chandran LR, Wan Mohamad WB, Wan Nazaimoon WM, Letchumanan $G R$, Jamaiyah $H$. Prevalence of Diabetes in the Malaysian National Health Morbidity Survey III 2006. Med J Malaysia 2006; 65(3): 173-179.

4. The Star Online. Diabetes-the new Malaysian epidemic?, 2012 [cited 2012 Nov 30]. Available from http://thestar.com. my/health/story. asp?file $=/ 2012 / 7 / 22 / h$ ealth/11702759\&sec $=$ health

5. Mafauzy M. Diabetes mellitus in Malaysia. Med $J$ Malaysia 2006; 61 (4): 397-413.

6. Wan Norlida I, Syed A, Aniza I. Cost of Type 2 Diabetes Mellitus in Selected Developing Countries. Malaysian J Public Health Med 2010; 10(2): 68-71.

7. American Diabetes Association. Standard of Medical Care in Diabetes. Diabetes Care 2012; 35(1): S11-S63.

8. Barnett $A H$, Cradock $S$, Fisher $M$, Hall $G$, Hughes $E$, Middleton A. Key considerations around the risks and consequences of hypoglycaemia in people with type 2 diabetes. Int J Clin Pract 2010; 64 (8): 1121-1129.

9. Kushner $P$. Minimizing the risk of hypoglycemia in patients with type 2 diabetes mellitus. Diabetes Metab Syndr Obes Target Ther 2010; 3: 49-53.
10. Amiel SA, Dixon T, Mann R, Jameson K. Hypoglycaemia in Type 2 diabetes. Diabetic Med 2008; 25(3): 245-254.

11. Tomky D. Detection, prevention, and treatment of hypoglycemia in the hospital. Diabetes Spectr 2005; 18(1): 39-44.

12. Krinsley JS, Grover A. Severe hypoglycemia in critically ill patients: Risk factors and outcomes. Crit Care Med 2007; 35(10): 2262-2267.

13. Briscoe VJ, Davis SN. Hypoglycemia in Type 1 and Type 2 Diabetes: Physiology, Pathophysiology, and Management. Clin Diabetes 2006; 24(3): 115-124.

14. American Geriatrics Society. American Geriatrics Society updated Beers Criteria for potentially inappropriate medication use in older adults. J Am Geriatr Soc 2012; 60(4): 616-631.

15. Umpierrez GE, Smiley $D$, Jacobs $S$, Peng L, Temponi $A$, Mulligan P. Randomized study of basal-bolus insulin therapy in the inpatient management of patients with type 2 diabetes undergoing general surgery (RABBIT 2 surgery). Diabetes Care 2011; 34(2): 256-261.

16. Chan SP, Ji LN, Nitiyanant $W$, Baik SH, Sheu SHH. Hypoglycemic symptoms in patients with type 2 diabetes in Asia-Pacific-Real-life effectiveness and care patterns of diabetes management: The RECAP-DM study. Diabetes Res Clin Pract 2010; 89(2): e30-e32.

17. Centers for Disease Control and Prevention. National diabetes fact sheet: National estimates and general information on diabetes and prediabetes in the United States, 2011. Washington D.C: US Department of Health and Human Services; 2011.

18. Epstein M. Diabetes and hypertension: the bad companions. J Hypertens 1997; 15: S55-S62.

19. Rajbharan Y, Pramil T, Ethiraj D. Risk factors and complications of type 2 diabetes in Asians. Curr Res Info Pharm Sci 2008; 9(2): 8-12.

20. John CR, Kit FN, Hnin HA, Dennis WW. Role of triglyceride-rich lipoproteins in diabetic nephropathy. Nat Rev Nephrol 2010; 6: 361-370.

21. Jisieike NN, Unuigbe El, Kalu OA, Oguejiofor $C O$, Onuigbo PC. Prevalence of dyslipidemia among adult diabetic patients with overt diabetic nephropathy in Anambra state South-East Nigeria. Niger J Clin Pract 2011; 14(2): 171-175.

22. Ministry of Health Malaysia. Clinical Practice Guidelines for: Management of type 2 diabetes mellitus. 4th ed. Putrajaya: Ministry of Health Malaysia; 2009.

23. Bertoni AG, Saydah S, Brancati FL. Diabetes and the risk of infection-related mortality in the US. Diabetes Care, 2001; 24(6): 1044-1049.

24. Mafauzy M, Hussein Z, Chan SP. The Status of Diabetes Control in Malaysia: Results of DiabCare 2008. Med J Malaysia 2011; 66(3): 175-181.

25. Shah N, Amanullah A, Afridi MH, Jamal S, Marwat MA. Prevalence, Risk Factors and Outcomes of Hypoglycemia in Elderly Diabetic Patients. JPMI 2012; 26(3): 272-276.

Trop J Pharm Res, June 2016; 15(6): 1319 
26. Alagiakrishnan K, Mereu L. Approach to managing hypoglycemia in elderly patients with diabetes. Postgrad Med 2010; 122(3): 129-137.

27. Stratton IM, Adler AI, Neil HAW, Matthews DR, Manley SE, Cull CA. Association of glycaemia with macrovascular and microvascular complications of type 2 diabetes (UKPDS 35): prospective observational study. BMJ 2000; 321(7258): 405-412.
28. Grandvuillemin A, Jolimoy G, Authier F, Dautriche A, Duhoux F, Sgro C. Tramadol-induced hypoglycemia. 2 cases. Presse Med. 2006; 3512(1): 1842-1844.

29. Taugourdeau S, Chiche L, Rouby F, Default A, Boyer M, Castellan D. Severe hypoglycemia induced by tramadol: two new cases of an unlisted side effect. Rev Med Interne 2011; 32(11): 703-705.

30. Faskowitz AJ, Kramskiy VN, Pasternak GW. MethadoneInduced Hypoglycemia. Cell Mol Neurobiol 2013; 33(4): 537-542. 